\section{Providing specialised services for anorexia nervosa}

\author{
R. L. PALMER and J. TREASURE
}

The commissioning of specialist services for severe anorexia nervosa has become the responsibility of National Health Service (NHS) Regions in England and Wales following the changes envisaged in the White Paper, The New NHS (Department of Health, 1997). Hitherto, provision had been first scarce and then patchy. The internal market for health care promoted by an earlier White Paper had stimulated the setting up of new services in two ways. Directly, it had fostered the creation of new services in the private sector. These were mainly in-patient units and much of their income came from treating NHS patients as extracontractual referrals. Indirectly, this flow of funds to the private sector - often for the treatment of small numbers of severely ill patients at high cost - provoked the setting up of local NHS services. These tended to be out-patient based and did not always avoid in practice the outflow of funds that, in principle, they were designed to staunch. The new commissioning arrangements should substitute rational planning for the vagaries of what was always a distorted and imperfect market.

\section{HISTORY OF SERVICES}

There have been major shifts in the way that anorexia nervosa has been thought about and managed over the years. The early medical descriptions of anorexia nervosa by Gull and Lasegue ushered in an era in which the disorder was managed predominantly by physicians. Gradually over the second half of the 20th century psychiatrists have come to take the predominant role. From the 1960s a few academic psychiatrists developed specialised services for anorexia nervosa, but provision was limited. As recently as 1992 , a report from the Royal College of Psychiatrists found only 21 centres providing specialist treatment for eating disorders, and large areas of the UK were without ready access to such care (Royal College of Psychiatrists, 1992). Over the past 15 years or so, there has been a rise in in-patient admissions for anorexia nervosa. Many of these have been repeated admissions. It is debatable whether or not there has been an increase in true incidence (Fombonne, 1995; Turnbull et al, 1996). However, there has almost certainly been a true rise in incidence of bulimia nervosa and this has added to the pressure for more services for treating eating disorders in general (Turnbull et al, 1996; Van Hoeken et al, 1998). It is this increasing demand that triggered the recent unplanned burgeoning of services and confronts those charged with planning rational provision for the future. But what should such rational provision look like? What problems do service provider's face?

Any rational provision for those suffering from anorexia nervosa must take account of a number of awkward facts and issues. Firstly, the disorder presents with a wide range of severity. There are those who still think of it as no more than the silly behaviour of spoilt girls, and mild cases do occur. However, overall, anorexia nervosa is a serious disorder with a mortality of around $0.6 \%$ per year - the highest of any functional psychiatric disorder (Nielsen et al, 1998). Approximately half of the deaths result from medical complications and the remainder are suicides (Herzog et al, 1992).

Furthermore, about one-third of cases run a truly chronic course and in them there is an accumulation of physical and psychosocial morbidity. The frustration and hopelessness associated with chronic severe cases can lead to extreme solutions. For example, euthanasia was practised on one case in The Netherlands (Vandereycken,

\section{SOME PROBLEMS}

1998) and in the UK there has been a heated debate about the possible place of palliative care in a hospice setting (Ramsey \& Treasure, 1996; Williams et al, 1998). Comprehensive services should provide for everything from the teenager going through a mild and potentially transient dip to the sufferer who is trying to live with the consequences of decades of disorder.

The second awkward issue is that sufferers from this serious condition often do not readily adopt the sick role. They are usually ambivalent and, at worst, resistant to attempts to help them to change. Yet at the same time, instrumental treatments are not available and some measure of cooperation between patient and clinician is essential. Squaring this circle is arguably the most difficult part of the management of anorexia nervosa. It certainly complicates both the planning of care for the individual and the formal evaluation of treatments in both audit and research. Furthermore, the tendency of some sufferers to hide away tends to make the estimate of true prevalence of the disorder - and hence potential need for services-more difficult than it might otherwise be.

A third fact about anorexia nervosa is that the range of typical age of onset spans the conventional division between services for children and adolescents and services for adults. Furthermore, because the disorder tends to last for years, those who present appropriately to the first may well need to graduate to the second during their illness career.

A fourth issue is that anorexia nervosa is a disorder with difficult psychological and physical aspects. Neither can be neglected if services are to be optimal or even safe.

Lastly, those charged with commissioning rational services will soon find that they are confronted with a barrage of opinion but precious little hard evidence about what is good and effective treatment for anorexia nervosa. They will not be able simply to confront potential providers with the prescriptions of evidence-based practice and tell them to get on with it. On the other hand, it is hardly ethical to refuse to provide for people suffering from such a severe and potentially life-threatening disorder. It is important that they examine what evidence there is, rather than throw their hands up in horror at the dearth of randomised controlled trials. Indeed, such trials themselves have important limitations in 
principle when used to evaluate treatments in a field such as this (Treasure \& Kordy, 1998). So what do we think we know?

\section{PROVISION OF CARE}

Overall, it may be useful to distinguish three aspects of the provision of care for people with eating disorders: clinical management, which refers to the means and methods used to help with weight gain and to treat comorbidity such as hospital admission, day programme attendance and, at minimum, out-patient contact; therapy, which refers to interventions designed to change psychological issues; and service organisation, which refers to the framework within which therapy and clinical management occur.

\section{Clinical management}

Most clinicians would agree that weight gain and, indeed, restoration of a healthy body weight can be achieved in almost all cases if the sufferer receives in-patient treatment in an experienced centre. These are more difficult to achieve on a one-off basis. Neither a general psychiatric nor a medical setting can guarantee to offer the appropriate type of care. The key factors are the confidence and culture of the treatment team, particularly the nursing staff. Management of a sufferer who is both very severely ill and a reluctant patient demands considerable skill and expertise.

Even though weight restoration may be readily - if expensively - achieved in hospital, it is also the case that many sufferers are able to regain weight with out-patient treatment alone. This is the case with about three-quarters of anorexia nervosa sufferers presenting to the Eating Disorders Services in Leicester and South East London. Special day care programmes may provide a compromise between in- and out-patient care. Limited experience suggests that they may be helpful (Kaplan \& Olmsted, 1997) but there is little hard evidence about which patients are best admitted and which are not. One study that compared different styles of clinical management found few differences between in-patient and outpatient management when the results were analysed on an intention-to-treat basis (Crisp et al, 1991). However, adherence to the allocated management was poor, so it is difficult to interpret these results. This does suggest that some patients may be able to recover with only modest amounts of help. Given the wide range of severity and the expense of many options, there has been interest in trying to find factors to match patients to the appropriate level of care. Weight and the response of weight to treatment in the short term may be predictors of outcome (Hebebrand et al, 1997). The managed care committee of the Academy of Eating Disorders has produced a draft document in which criteria for matching patients to the appropriate level of care have been suggested. The 'necessary and sufficient' criteria include the assessment of medical complications, suicidality, weight and motivation to recover. However, this is based upon clinical pragmatism rather than scientific evidence. In practice, physical severity and failure to respond to out-patient treatment are the most usual indications for offering admission.

\section{Therapy}

Clinical experience suggests that some kind of psychotherapy is beneficial. Indeed, most of the few data from randomised controlled trials in the treatment of anorexia nervosa concern the differential effects of different kinds of psychotherapy. Most of the studies have had low power but there are broadly consistent trends between studies. For example, it is helpful to involve the family of young patients (Dare \& Eisler, 1995). Furthermore, specific psychotherapy based either on cognitive-behavioural or psychodynamic principles is more effective than non-specific supportive management either by a psychiatrist or a dietician (Treasure \& Ward, 1997).

\section{Service organisation}

Service organisation is often best understood in terms of history and politics. The situation in the UK was described in the introduction. The range of services provided in Europe is widely divergent. For instance, in Germany, anorexia nervosa is treated not by psychiatrists but by psychosomatic doctors - a specialisation that flourished after psychiatry became tainted because of the links with the Nazi regime. Clinicians working in private practice have prevented hospitals from developing outpatient programmes and so the majority of care for both anorexia nervosa and bulimia nervosa is on an in-patient basis, often using a psychoanalytical model. In Italy, however, there are few specialised in-patient units for anorexia nervosa. When the free medical market flourished in the USA, in-patient treatment was the norm. Indeed, clinical guidelines by the American Psychiatric Association (1992) recommend in-patient treatment for anorexia nervosa in all except mild, highly motivated cases. Notwithstanding this prescription, sustained in-patient care is becoming difficult to arrange in the USA because of lack of support from third-party funders. Overall, it is unclear whether these differences in service provision affect outcome. Work in progress from the European COST study may provide some of the answers (Treasure \& Kordy, 1998). Meanwhile, there is a hint that areas without specialised services may have a higher mortality (Crisp et al, 1992).

\section{PROBLEMS OF PROVISION}

Problems in providing adequate help for people with anorexia nervosa may arise in relation to any of the three issues mentioned above. Different clinical services may experience different aspects of provision as problematic: for some, psychotherapeutic skills may be in short supply; for others, providing intensive in-patient care may be difficult or impossible; and for many, the problem is one of developing a service organisation that is able to provide continuity of therapy together with the ability to provide more intensive care as an additional means to change when necessary. As an example, services that lack beds may have to hand over care to distant in-patient services if admission is required, or a specialist in-patient unit may undertake the treatment of a severely ill sufferer but may have difficulty in following this with ongoing therapy. In either case there is potentially damaging discontinuity of care. Neither the purely out-patient service nor the distant in-patient unit can claim to provide optimal care for many sufferers. Nor should they do so, although it must be a temptation for hard-pressed commissioners to enter into collusion with overambitious providers and not think too much about the gaps in the service. The advent of regionally based specialist commissioning may or may not improve matters. How are these issues best addressed?

\section{WAYS FORWARD}

Goldberg \& Gournay (1997), in their discussion document on the design of mental 
health services, put anorexia nervosa into the category of a severe mental illness requiring specialised services. Nevertheless, some treatment will occur in primary care or in generic specialist care. The optimal balance between these two kinds of provision is unclear and may vary according to circumstances. There is always a tension between the drive to provide specialist services for less common conditions and the need for the generalist to provide accessible, equitable and local services. Local and general services may well be most appropriate for mild cases or for chronic, stable anorexia nervosa. The merits of specialised services are that they have the confidence and skills to develop new interventions and the resources to evaluate them. The user benefits not only from high-quality staff skills but also from the experience of contact with other sufferers. The disadvantages of specialist services are that they may be geographically remote and the related generic teams lose the opportunity to increase their skills through experience. However, in the field of anorexia nervosa, generic services and community teams are likely to find it difficult to build up sufficient experience, skill and confidence to deal with at least some sufferers. Such confidence comes through intensive experience, training and supervision. This is true for out-patient treatment.

There is even more difficulty in building sufficient experience in more intensive forms of treatment such as in-patient or special day care. Such treatments are much easier to manage in specialist units, which have a number of patients in treatment together. There is likely to be a minimum size of population that supports such a unit. The incidence of new cases of anorexia nervosa presenting to primary care is about seven per 100000 population (Turnbull et al, 1996; Van Hoeken et al, 1998), which means that approximately 4000 new cases arise in the UK every year. If about one in four sufferers requires specialist in-patient care, a unit set up to provide such care is likely to need to serve a population of at least one million. The population required to sustain an equivalent special service for children and adolescents will be even bigger. Below the age of $\mathbf{1 6}$ years the prevalence of disorder declines sharply and, furthermore, in-patient care is indicated for a smaller proportion of this smaller number. However, it is important that the special needs of such younger sufferers are addressed. When in-patient care is required,

R. L. PALMER, FRCPsych, University of Leicester Department of Psychiatry, Brandon Mental Health Unit. Leicester General Hospital, Leicester: J. TREASURE, FRCPsych, Eating Disorders Unit, Institute of Psychiatry. London

Correspondence: Dr J. Treasure, Eating Disorders Unit, Institute of Psychiatry. De Crespigny Park. Denmark Hill, London SE5 8AF, UK

(First received 4 Janaury 1999, final revision 8 April 1999, accepted 8 April 1999)

admission to a unit focused on adult sufferers is not appropriate. However, given appropriate specialist staffing-medical, nursing, educational and other - an inpatient unit that was designed to accept all but the very youngest patients might be an acceptable compromise. The care of very severe eating disorders in children under 14 years of age must be considered a highly specialised enterprise.

\section{A new model of care provision}

The Audit Commission propose that specialised services should be planned and coordinated (Audit Commission, 1997). They advocate a 'hub and spoke' model with a centralised element providing very specialised health technology (in the case of eating disorders - in-patient beds or other intensive care) with several 'feeder' clinics possibly providing 'franchised' care. The process of recovery from anorexia nervosa will always last longer than admission, and continuity of personal care is important. The relationship between the specialist centre and those in local services - the hub and the spoke - needs to allow intensive management (admission or special day care) to be added without undue disruption to an ongoing process of personal therapy when they are required as additional means. There is room for variety in service organisation with respect to how this is achieved: for instance, by using joint posts between hub and spoke or by basing the key clinicians at the hub. The aim is to form a disease management programme operating across the boundaries of primary, secondary and community care. Such a move would end the era of a deregulated system of independent practitioners. The specialised service would be responsible for clinical governance with their area and would have the responsibility to provide outcome measures and quality control. The hubs would also be centres for training and research. Data collected by all centres could be used, in principle, to shape the specialised services into evidence-based models of managed care. The utopian aim would be for the standard of the whole provision for anorexia nervosa to be raised through a combination of innovation, evaluation and generalisation of good practice. The time is overdue for improved and consistent care to be widely available for this pernicious and underestimated condition that blights so many young lives.

\section{REFERENCES}

American Psychiatric Association (1992) Practice guidelines for eating disorders. American journal of Psychiatry, 150. 208-228.

Audit Commission (1997) Higher Purchase; Commissioning Specialised Services in the NHS. London: Audit Commission.

Crisp, A. H., Norton, K., Gowers, S., et al (1991) A controlled study of the effect of therapies aimed at adolescent and family psychopathology in anorexia nervosa. British journal of Psychiatry. 159. 325-333.

— , Callender, J. S., Halek, C., et al (1992)

Long-term mortality in anorexia nervosa. A 20 -year follow-up of the St George's and Aberdeen cohorts. British Journal of Psychiatry. 161. $104-107$

Dare, C. 2 Eister, I. (1995) Family therapy. In Hondbook of Eating Disorders: Theory. Treatment and Research (eds G. Szmukler, C. Dare \& J. Treasure). pp. 333-349. Chichester: Wiley.

Department of Health (1997) The New NHS: Modern, Dependable, CM 3087. London: HMSO.

Fombonne, E. (1995) Anorexia nervosa. No evidence of an increase. British journal of Psychiatry. 166. 462-47I.

Goldberg, D. \& Gournay, K. (1997) The General Proctitioner, the Psychiotrist and the Burden of Mental Health Core. Maudsley Discussion Paper No. I. London: Institute of Psychiatry.

Hebebrand, J., Himmelmann, G.W., Herzog, W., et of (1997) Prediction of low body weight at long term follow-up in acute anorexia nervosa by low body weight at referral. Americon journal of Psychiotry. 154, 566-569.

Merzog, W., Deter, H. C., Schellberg, D., et al (1992) Somatic findings at 12 year follow-up of 103 anorexia nervosa patients. In Follow-up - in the Course of Eating Disorders (eds W. Herzog. H. C. Deter \& W. Vandereycken). pp. 85-107. Berlin: Springer Verlag.

Kaplan, A. S. \& Olmsted, M. P. (1997) Partial hospitalisation. In Handbook of Treatment of Eating Disorders (2nd edn) (eds D. M. Garner \& P. E. Garfinkel). pp. 354-360. New York: Guilford. 
Nielsen, S., Moller-Madsen, S., Lager, T., et al (1998) Standardised mortality in eating disorders a quantitative summary of previously published and new evidence. Journal of Psychosomatic Research, 44 413-434.

Ramsey, R. \& Treasure, J. (1996) Treating anorexia nervosa (psychiatrists have mixed views on the use of terminal care for anorexia nervosa). British Medical Journal, 312, 182.

Royal College of Pyychiatrists (1992) Eating Disorders. Council Report CRI4. London: Royal College of Psychiatrists.
Treasure, J. L. \& Ward, A. (1997) Cognitive analytical therapy (CAT) in eating disorders. Clinical Psychology and Psychotherapy, 4, 62-71.

- Kordy, H. (1998) Evidence based care of eating disorders: beware the glitter of the randomised controlled trial. European Eating Disorders Review, 6. 85-95.

Turnbull, S., Ward, A., Treasure, J., et al (1996) The demand for eating disorder care. An epidemiological study using the general practice research database. British journal of Psychiatry, 169, 705-712.
Vandereycleen, W. (1998) Whose competence should we question? Europeon Eating Disorders Review, 6. $1-3$

Van Hoeleen, D., Lucas, A. R. \& Hoek, H. W. (1998) Epidemiology. In The Integration of Neurobiology in the Treatment of Eating Disorders (eds H.W. Hoek J. Treasure \& M. Katzman), pp. 97-126.Chichester: Wiley.

Williams, C. J., Pieri, L. \& Sims, A. (1998) We should strive to keep patients alive. British Medical Journal, 317. 195-197. 